\title{
MODELLING OF THE BUILDING PROCESS IN CONSTRUCTION PLANNING AND MANAGEMENT USING I. T.
}

\author{
Čeněk Jarský \\ Faculty of Civil Engineering, Czech Technical University, Prague, Czechia \\ jarsky@fsv.cvut.cz, jarsky@contec.cz
}

\begin{abstract}
The paper describes the main principles and results of the integrated cost estimation and project management microcomputer system developed in the last years on the base of the spatial, technological and time analysis of the building process with use of the methodology of the construction technology design. This expert system is based on quick modelling of the building process by use of typical network diagrams, which are prepared in advance, created by an original construction technology network diagram method. The typical network diagrams can be modified according to the spatial conditions of a certain building and to the amount of construction works and materials. Thanks to the database of construction processes and to the typical network diagrams the model of the building process including the cost assessment can be made about 50 times quicker than by use of current cost estimation or project management systems, quality assurance checklists, environmental plans and plans of the safety at work included.
\end{abstract}

KEYWORDS: construction technology, building process model, network analysis, project management

\section{INTRODUCTION}

When projects are to be undertaken it is necessary to visualise all the operations of the project, arrange these operations in their proper sequence, achieve confidence that every participant of the building process (the owner, the architect and the contractor) understands each of his tasks, acquires the know-how and means necessary to perform them and feels convinced that the method chosen for performing all tasks is the most progressive and economical. Thus all projects have to be efficiently planned at the investor's (owner's), architect's and contractor's sides. In the planning and design stage of the project several specific problems must be solved and many points of view have to be taken into this decision process. A lot of these questions including the cost assessment can be efficiently solved by creating of a computer model of the flow of the building process of the structure. The model must be based on the construction technology and cost analysis of the building process including the analysis of the spatial, technological and time structure, see Jarský et al. (2003), and must reflect all of the main points of view and architectural, technical, technological and economical links of the building process.

The market conditions in building industry force further every contractor to be able to react very quickly while making his bid to the requests of the investor for getting the order, including the cost analysis. Therefore the contractor must have means that are capable to create the basic documents of the bid, e. g. price and technology analysis, time schedule of 
the proposed building process, selection of basic means of production (machines, labour) etc. The linkage to the quality assurance system appears here even in the first stage of planning of the project, see Gašparík (1999). It is desirable to be able to make use of the documents made during the bidding process further for actual management of construction processes on site and for quality assurance of the whole project after a certain contractor was selected. To make such evaluations as precise and quick as possible an expert computer based project planning and management system, named CONTEC, has been developed, which is capable to model very quickly not only the building process of the project itself, including the cost and other resource analysis with quality assurance checklists, environmental plans and plans of the safety at work, but simultaneously the process of maintenance and reconstruction needed in the years to come, or even the process of demolition if need be (Jarský, 2000).

\section{BASIC REQUIREMENTS ON THE BUILDING PROCESS MODEL}

The feasibility study of the developer must answer some main questions, among others especially what the price of the project will be, what the time schedule and flow of the building process will be and whether it is possible to keep the required deadline of the project from the technological point of view. The total desired time of service and the quality level has to be stated too. It is desirable for the investor to have the possibility to model even some contractor's data about the building process of the project, especially what the actual cost for the project will be and therefore the resulting profit, how many craftsmen in special professions are necessary, what sorts of machinery and when they are needed on site, how the cash flow and finances will be secured in proper terms and how the quality of the project and its parts will be assured and controlled, see Makýš (2002).

With the help of the CONTEC system the investor has the possibility to simulate the proposed time and resource flow of the building process of the project on a microcomputer even if the topical relevant data about the project in the planning stage are very poor. The more precisely the task is determined the better results can be obtained from the model. On the base of the typical network diagrams and database of construction processes a model of the actual erection of a buildings and a model of its maintenance and reconstruction can be automatically created. After completing the model the investor can decide about actual resource allocation in time according to the whole time of service (including the influence of inflation) and maintenance and reconstruction cycles needed according to durability of constructions used in the buildings. The model of the building, maintenance and reconstruction process is based on the main documents of the construction technology design.

\section{ON METHODOLOGY OF THE CONSTRUCTION TECHNOLOGY DESIGN}

The methodology of the automated creation of the basic documents of the construction technology design is described in Jarský (2000). The main documents in construction technology design include files of technological standards, sometimes called as technological analysis sheets or programmes, and network diagrams. The close link between these documents which is used in the CONTEC expert system enables to elaborate bar charts, lineof-balance graphs, allocation graphs of different technological and economical resources and quality assurance checklists, environmental plans and plans of safety at work. Hitherto the 
said documents, on one hand technological standards (programmes) and on the other hand network diagrams have been mostly processed subsequently, separately. Their close construction technology relationship has been often disregarded and network diagrams have been elaborated without consistent technological analysis and synthesis contained a number of errors which made them useless for construction project control with all consequences thereof, regarding economical, time and quality losses. Quality assurance checklists, environmental plans and plans of safety at work have been not usually elaborated at all or by separate divisions with no connection to the actual flow of the building process. The simultaneous elaborating of technological standards, network diagrams, cost analysis and quality assurance checklists, environmental plans and plans of safety at work used in the CONTEC expert system, eliminates the processing of network diagrams without the technological analysis and synthesis of all three structures of the building process and makes possible to use the close link between technological standards and documents for quality management, environmental management and safety at work management in the project.

The technological standard (technological analysis sheet or programme) determines the technological structure of the production process (sequence of construction processes, volume of production, labour and cost consumption, number and profession of workers or machines etc.). According to the calculated network diagram the technological standard includes a bar chart which indicates the time structure of the production process. Further a technological scheme showing the spatial structure of the process is usually added. The connection between the time structure and the spatial structure of the building process can be seen in the line-of-balance graph (time-space graph). The quality assurance checklist which is automatically created according to the technological standard consists of instructions for performing the quality checks of the resulting product at every significant construction process, similarly the environmental and safety at work plans.

According to the values of the duration of the processes and the minimum working space necessary it is possible to determine (with regard to the direction of the course of processes) the critical approximation of construction processes and to link these processes immediately in the optimum way in the construction technology network diagram method with regards to the condition of the quality of the resulting products of construction processes. Thus all documents mentioned above after the network diagram calculation depict floats of the construction processes. Floats are subsequently used for the optimisation of the building process from the point of view of limited resources in different time periods.

\section{LINKS IN THE CONSTRUCTION TECHNOLOGY NETWORK ANALYSIS METHOD}

The construction technology network analysis method used by the expert system was designed for simultaneous evaluating of technological standards and network diagrams and for the optimisation of linking the construction processes from the point of view of maximum use of minimum working space on site necessary for the efficient, economical and safe performing of construction processes including technological pauses. This network analysis method uses the activity-on-node network diagram. All four types of links of activities introduced in the precedence graph method (finish - start, start - start, finish - finish and start - finish), see Ahuja (1976), were included in the construction technology network analysis method too. The main disadvantage of the precedence graph method is the necessity to know 
the actual values of lag times between every two activities that are linked together and their duration while creating the network diagram. This would make the concurrent evaluation of the technological standard and of the network impossible.

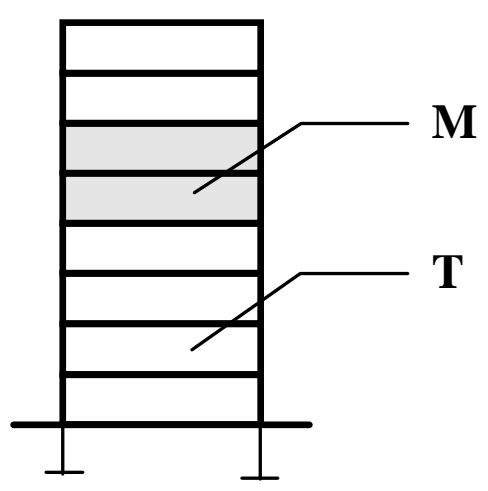

M - minimum working space

$\mathrm{T}$ - total working space available

$\mathrm{f}$ - working space index

$\mathrm{f}=\frac{\mathrm{M}}{\mathrm{T}} \bullet 100 \quad[\%]$

Figure 1: Working space index

Therefore the construction technology network analysis method introduces the 5th type of link, the construction technology link, that results from the condition of release of the minimum working space on a structure by the previous work gang so that the following work gang could start as soon as possible. The lag time is not given by a certain time value but it is calculated by the computer according to the duration of linked activities and to the spatial structure of the building, which is represented by a working space index $f$. This index is determined by the ratio of the minimum working space needed for the gang divided by the total working space in the building, e. g. in a 8 storey administrative building the usual minimum working space are 2 floors, so the working space index $\mathrm{f}$ is $2 / 8$, that is $25 \%$, see fig. 1. Introducing this link in the CONTEC method means not only a simplification of inputting the data of the network diagram but it permits a wide formation and utilisation of typical network diagrams as computer files for the erection, maintenance and reconstruction of different sorts of buildings with the possibility of their modification according to the spatial structure of the actual building. There are usually only three main types of working space for different activities on site $\left(f_{1}\right.$ for subterrain structure or works on the roof, $f_{2}$ for erection and plumbing, $f_{3}$ for finishing works). Thus only three values of the main working space indexes are sufficient to evaluate practically all technological constraints in the building process. In the typical network diagram the values of the working space indices are given parametrically. While stating data about the actual building the typical network diagram can be modified by stating of the 3 main working space indices only.

The situation of linking two processes of technological stage $i$ and $j$ is illustrated in the lineof-production graph on fig. 2 a, b. Each process of technological stage (e. g. foundation, superstructure etc.) consists of several construction processes (working gangs, e. g. formwork, reinforcement, concrete laying etc.). Values $t_{i}$ and $t_{j}$ represent the duration of processes of technological stage, $\mathrm{T}^{\prime}{ }_{\mathrm{i}}$ and $\mathrm{T}^{\prime}{ }_{\mathrm{j}}$ their time of launching, $\mathrm{TP}_{\mathrm{i}}$ the technological pause after completing the $\mathrm{i}$ activity, $\mathrm{f}_{\mathrm{ij}}$ is the working space index. In the first case (fig. $2 \mathrm{a}$ ) if the last construction process in the preceding process of technological stage i is shorter, than the first construction process in the following process of technological stage $j$, the lag time $\varepsilon$ can be automatically calculated according to formula (1). 
$\varepsilon=\left(\mathrm{t}_{\mathrm{i}}-\mathrm{T}^{\prime}{ }_{\mathrm{i}}\right) \cdot \mathrm{f}_{\mathrm{ij}}+\mathrm{T}^{\prime}{ }_{\mathrm{i}}+\mathrm{TP}_{\mathrm{i}}+\delta$

a) $\left(t_{i}-T^{\prime}{ }_{i}\right) \leq\left(t_{j}-T^{\prime}{ }_{j}\right)$

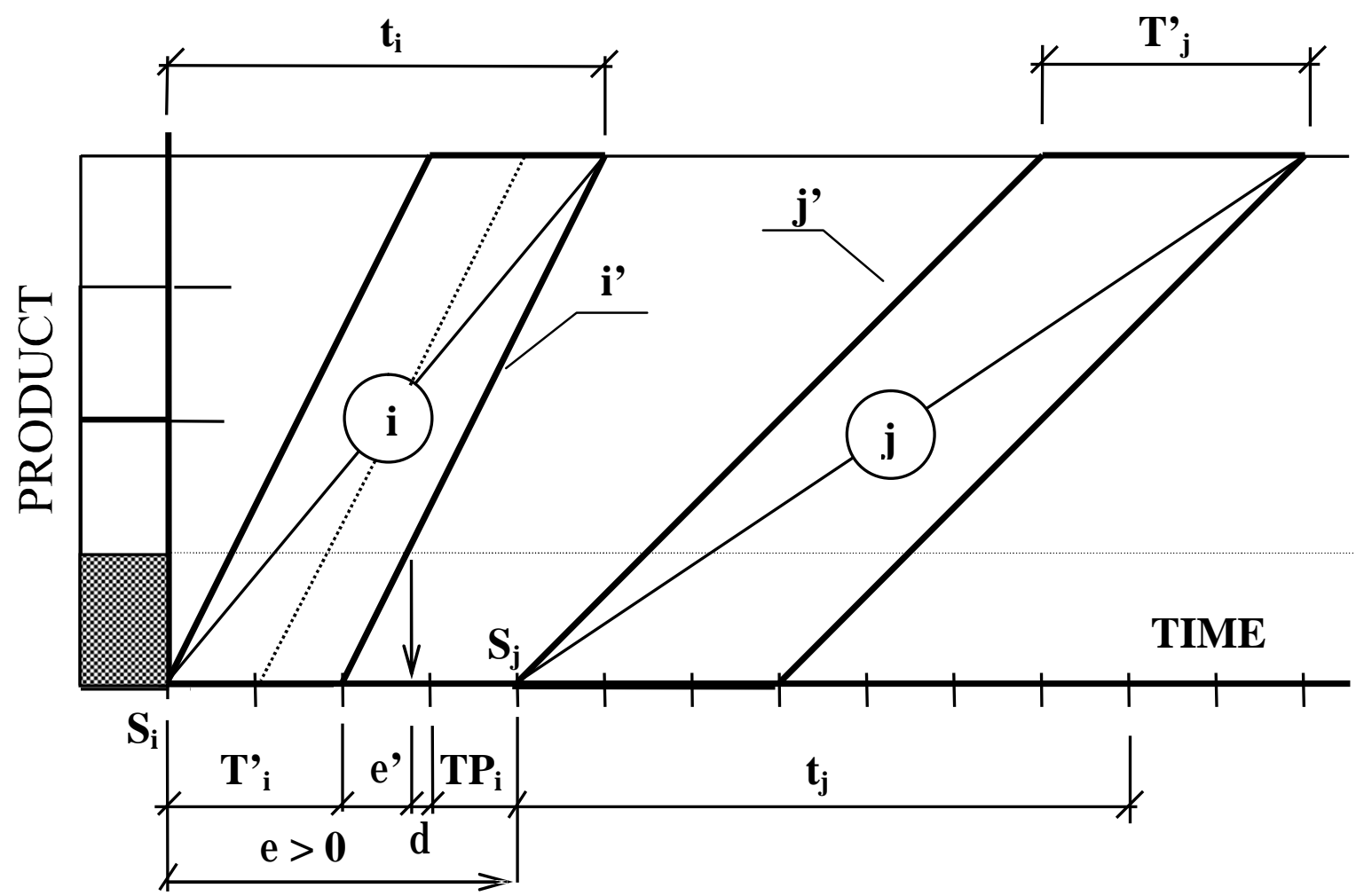

b) $\left(t_{\mathbf{i}}-\mathbf{T}_{\mathbf{i}}\right)^{\prime}>\left(\mathbf{t}_{\mathbf{j}}-\mathbf{T}_{\mathbf{j}} \mathbf{j}^{\prime}\right)$

$\varepsilon>0$

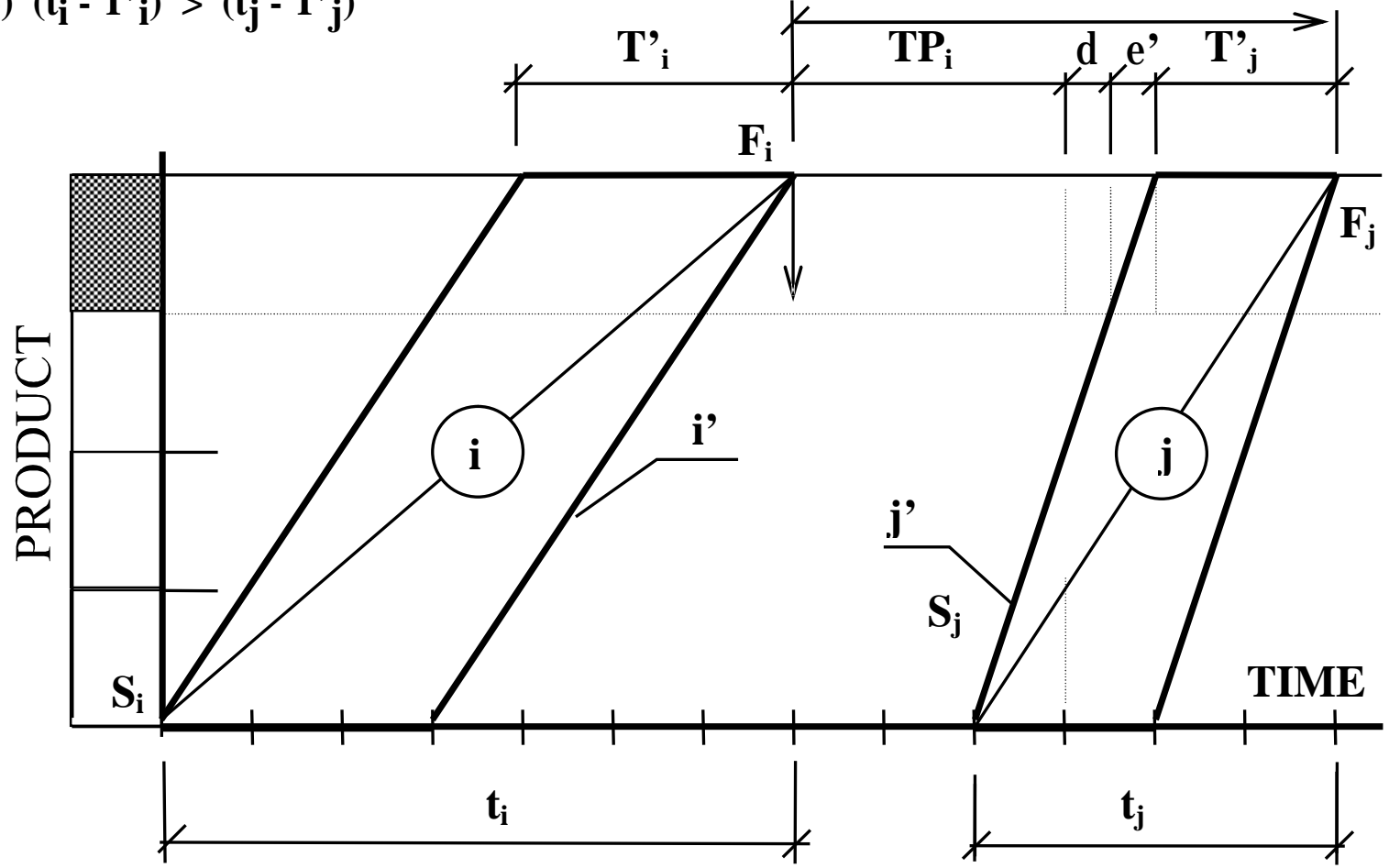

Figure 2: Principle of the construction technology link 
The $\delta$ value rounds the lag time to whole time units, so that the topical work gang would start their work at a certain time unit in the morning. If the first construction process in the following process of technological stage $\mathrm{j}$ is shorter than the last construction process in the preceding process of technological stage i, (fig. 2 b) then the lag time $\varepsilon$ is calculated according to formula (2).

$\varepsilon=\left(t_{j}-T_{j}^{\prime}\right) \cdot f_{i j}+T^{\prime}{ }_{j}+T_{i}+\delta$

In the time analysis of the network diagram using the construction technology link, the start of the following activity $\mathrm{j} \mathrm{S}_{\mathrm{j}}$ can be calculated during the forward calculation according to formula (3), the finish of the preceding activity i $F_{i}$ can be calculated during the backward calculation of the network diagram according to formula (4).

$$
\begin{aligned}
& \left.S_{j}=\max \left\{\left[S_{i}+\left(t_{i}-T^{\prime}{ }_{i}\right) \cdot f_{i j}+T^{\prime}{ }_{i}+T_{i}+\delta\right)\right] ;\left[S_{i}+t_{i}-t_{j}+\left(t_{j}-T^{\prime}{ }_{j}\right) \cdot f_{i j}+T^{\prime}{ }_{j}+T_{i}+\delta\right]\right\} \\
& F_{i}=\min \left\{\left[F_{j}-t_{j}-T_{i}+\left(1-f_{i j}\right) \cdot\left(t_{i}-T^{\prime}{ }_{i}\right)-\delta\right] ;\left[F_{j}-T^{\prime}{ }_{j}-T_{P_{i}}-f_{i j} \cdot\left(t_{j}-T^{\prime}{ }_{j}\right)-\delta\right]\right\}
\end{aligned}
$$

Further, the construction technology network analysis method introduces the 6th type of link, the flow link, that results from the condition of continuous course of a construction process on different products, e. g. sections, buildings etc. The 7th and 8th types of link, the partial links, describe the condition that a following activity can start (or must finish) after the completion of a certain part of the previous activity or vice versa. These links are determined by the partial link indices that represent the ratio of the duration of finished part of the previous activity divided by the total duration of the previous activity (type 7) or the ratio of the duration of unfinished part of the following process divided by the total duration of the following process (type 8). If this index is negative it represents the same ratio but for the following (type 7) or preceding (type 8) activity. Using the flow link modified typical network diagrams or evaluated network diagrams of buildings can be automatically linked into a greater network that may represent the building process of the whole project consisting of more buildings, e. g. a housing estate, an industrial plant, or its maintenance or reconstruction. In this case the flow links are generated by the system at activities that are performed by specialised work gangs that proceed continuously from one building to another. The network diagram can be calculated on the deterministic or stochastic base.

\section{MODELLING THE BUILDING PROCESS}

The main condition for modelling the erection, maintenance and reconstruction process is stating the task and intentions of the investor. Sometimes the investor has only very approximate imaginations what he wants to be built. In the very first stage he usually knows e. g. that there is an intention to build two concrete industrial halls, one about $40000 \mathrm{~m}^{3}$ of build-in space and the second with about $15000 \mathrm{~m}^{3}$ of space. He has some propositions and drafts about the layout and about the construction system. Later the investor usually has a certain level of design of the project including the bill of quantities which is very significant.

Then, a database for the quick modelling of the building process is available. This database consists of the main data about all construction processes at the technological structure of work gangs. It includes main facts about time standard, productivity of labour, price of the product, number of workers, technological pause and other 20 economical and technological resources (material costs, wages, costs for machines, overheads, average profit, machines, 
materials, professions etc.). For the possibility of quick making of the quality assurance checklists, environmental plans and plans of safety at work another databases of the checks of the quality of resulting products (what must be controlled, in which way, according to which standards etc.), environmental aspects and risks of safety at work were created. Theese databases are closely linked with the database of construction processes.

The typical network diagram of a building or maintenance process as a computer file contains the data about the sequence of the construction processes, and their linkage. It is preferable to use especially the construction technology link stated parametrically as much as possible, or other sorts of links with the lag time equal zero. Under these conditions the typical network diagrams can be easily modified according to the spatial structure of the actual building. The volume of production and costs and price of all activities that are included, too. They are related to an adequate custom-made measure unit, usually $\mathrm{m}^{3}$ of build-in space or $^{2}$ of reconstructed area in case of a reconstruction. As stated above the typical construction technology network diagram can be modified according to the spatial structure of the building process by using the 3 main minimum working space indices.

When the user simulates the building process he calls up in the very first stage the typical network diagram of the certain building, modifies it by stating the actual main working space indices and the computer generates the first draw model of the erection process, including the time and cost analysis data which are transferred from the database of construction processes. Thus, the user can get the first model much quicker than by the use of classical project management systems that require to create the network diagram by adding relevant activities one after another and stating their duration, resources and links. The created model has to be defined with more precision according to the facts known about the building. It is known that $80 \%$ of the price and costs is influenced by $20 \%$ of activities only. Volumes of production of these significant processes have to be stated according to the construction design, prices of the production, labour consumption and resources needed are calculated automatically according to the database of activities. If the exact bill of quantities is available its items and their values (quantities, price, labour consumption and economical and technological resources) can be automatically transferred into the model according to the technological division of labour. After the calculation of the network diagram the user gets the early and late terms of starts and finishes of all activities. Figure 3 illustrates a part of the resulting bar chart with main links of the construction technology network diagram with the analysis of budget items which were aggregated to the activity "Demolitions adaptational". The critical activities are drawn in red, non critical in green, the total float is illustrated by dotted line after the duration of a non critical activity.

By the change of number of workers in the gangs or by changing the tension index of time standards the duration of activities and thus the whole network diagram can be modified. Activities of all sorts (not only those from the database) can be included into the network. After making these models for all buildings that are included in the project it is possible to make a network diagram of the whole project by connecting the partial networks and linking them together with flow links in case of continuous work of specialised work gangs in linked buildings.

Thus, it is not necessary to create the network diagram individually from the very beginning for every project. The CONTEC system enables to build up the model of the building process of the project very quickly from prefabricated sections, typical network diagrams of different 
buildings, and to define it with more precision easily according to the facts gained from the investor's task. It can be easily updated in case of a change of different conditions. The network can be automatically recalculated from the point of view of keeping the deadline of the project required. The system then selects activities that have to be shortened by adding a certain number of workers or by increasing the intensity of work, while keeping technological rules and all links of the network.

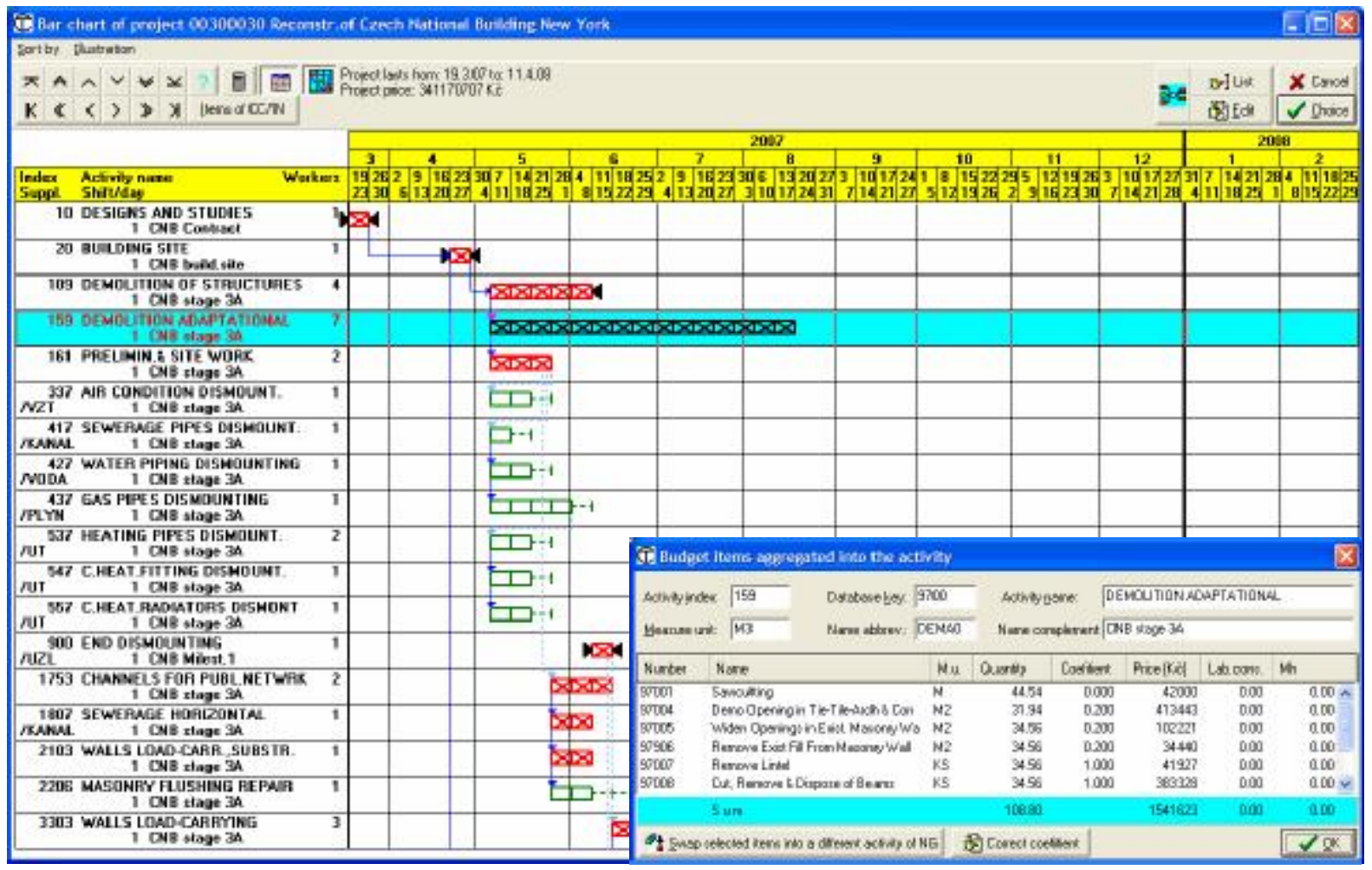

Figure 3: Part of a bar chart with ND links with overview of budget items aggregated into activity

Naturally all data included in the model can be interactively edited and recalculated. The system enables to print the calculated network diagram in different forms (technological analysis, bar chart, line-of-balance graph, resource allocation graphs of price, costs and cash flow, labour consumption, need of work force etc.), in Czech, English, Italian or Russian. Even in the very first stage of the plan it is possible to create the quality assurance checklist by the use of the database of quality checks. The particular network diagram can be then aggregated into the higher information level of technological stages, steps of completion or to the level of buildings. All documents that are gained on the base of the construction technology network diagram can be easily updated according to the actual completion of construction processes on site at a certain term. If there is a delay, the system suggests what measures are to be done to be able to keep the final deadline of the project. At the same time it keeps the technological rules of the building process. This can be visualised in the comparative bar chart, where the updated version of the building process drawn in bigger lines is compared in one document with the planned flow of the process.. According to the recalculated network diagram the line-of-balance graph can be automatically redrawn on the plotter. The outputs from the system are used for evaluation of operational plans on site and for operational registration with the link to the invoicing agenda. On the other hand, the operational registration files from the invoicing system can be used for automatic updating of 
the network diagram in the CONTEC system and then recalculating the terms of activities and of the operational plan. A new resource allocation balance is the result of the updated model of the building process. Quality assurance checklists, environmental plans and plans of safety at work are updated simultaneously in similar way from the point of view of terms of checks of all construction processes.

\section{PRACTICAL EXAMPLES OF USE}

The main documents of the construction technology and cost analysis created in the mentioned way can contain the model of the building process of the project that includes all necessary data for the building process control and management and resource allocation balancing. The described way of preparation and management was used in some cases of reconstruction of historical buildings and in a large number of significant new projects.

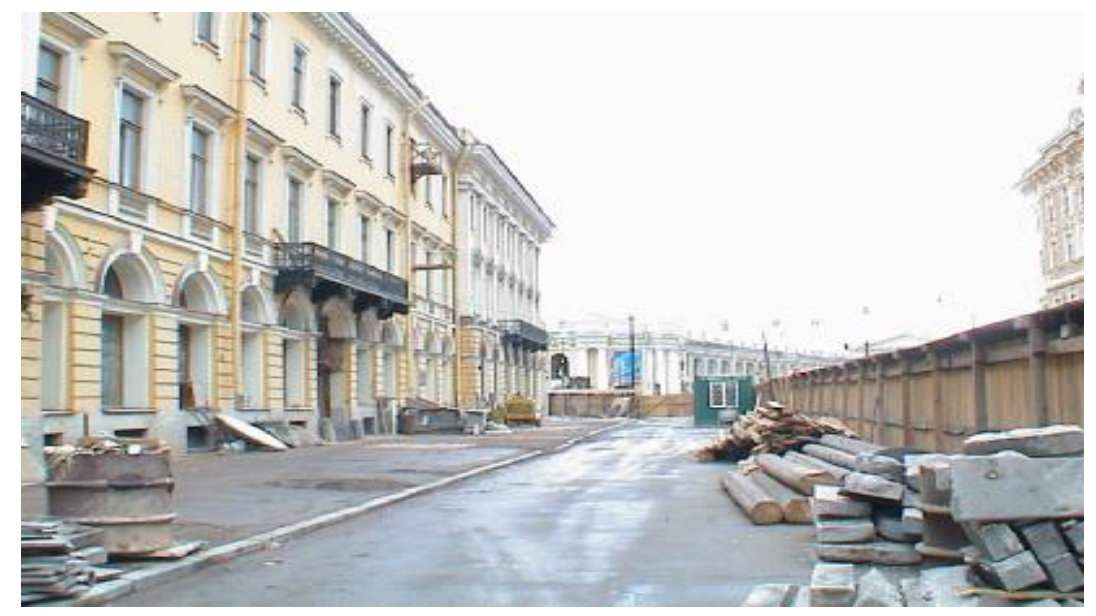

Figure 4: Promstroibank St Petersburg, Russia - north façade

An interesting example of the cost and time analysis performed by the CONTEC system was the reconstruction of the building of Industrial and Construction Bank at the Nevsky Prospect in St. Petersburg in Russia. The north façade of this building is illustrated on Figure 4. This building that was originally built at the end of 18th century completely burnt out in 1993. There were very difficult ground conditions on this site because it lies under the water level of the river Neva. The load bearing walls had to be underpinned by oblique piles, new diaphragm walls had to be built and a lot of injections and ground consolidation had to be performed. The south-east wing of the building was completely demolished and then erected in a new shape. All ceilings were demolished and rebuilt. A new glazed roof steel structure was built and all necessary technological equipment including safes and computer systems for the bank had to be replaced. In the construction technology and cost analysis the climate and weather conditions had to be respected as some of them had a very negative influence on the building process. Lots of changes were made during the reconstruction process and the model had to be updated regularly once in 2 months.

An example of new significant project is the Sazka arena in Prague - the biggest ice-hockey arena in Czechia. The system was used in the planning stage of the project for elaborating of the plan of the organization of the building process. 


\section{CONCLUSIONS}

The main documents of the construction technology design created by the help of the CONTEC system can contain the model of the building process of the project that includes all necessary data for the building or reconstruction process control and management. The system enables to create the building process model with appropriate cost assessment and time-cost analysis about 50 times quicker than current project management systems. Therefore it is possible to use the documents as a part of a feasibility study, bid, construction technology design and operative plan for the project management of the erection or reconstruction process itself. This model can be updated according to the bill of quantities or cost estimation. Afterwards the quality assurance checklist, the environmental plan and plan of safety at work can be automatically created. All documents that are gained from the system can be easily updated according to the actual completion on site at a certain term. If there is a delay, the system suggests what measures are to be done in the future to be able to keep the final deadline of the project. All documents can be automatically translated to Czech, Slovak, English, Italian and Russian.

The described system can be used on IBM PC compatible computers under Windows 9x, ME, NT, 2000, XP, Vista and 7 operational systems. Nowadays the CONTEC system linked with different cost estimation systems is used in more than 370 investor's and contractor's firms in the Czechia and Slovakia. The experience from the users is permanently used to the innovation of the system, now especially in the field of automatic modelling and planning of regular maintenance of buildings and calculating the utility of projects.

\section{REFERENCES}

Ahuja H. N. (1976) Construction Performance Control by Networks. Wiley, N. Y., USA

Gašparík J. (1999) Manažérstvo kvality v stavebníctve (Quality Management in Construction), Vydavatelstvo Jaga Group Bratislava, Slovakia

Jarský, Č. (2000) Automatizovaná příprava a řízení realizace staveb (Automated Preparation and Management of Realization of Structures), CONTEC Kralupy n. Vlt., Czechia.

Jarský, Č., Musil, F. et al (2003). Př́prava a realizace staveb (Preparation and Realization of Structures), Akademické nakladatelství CERM s. r. o., Brno, Czechia.

Jarský, Č. (2006) On Computer modelling of Building, Reconstruction and Maintenance Process, In Proceedings of 7th International Konference Organization, Technology and Management in Construction, Zadar, pp. 134 - 142, Croatian Association for Organization in Construction, Zagreb, Croatia.

Jarský Č. (2009) Modelling of buildings and projects with utility assessment, In Proceedings of 8th International Conference - Organization, Technology and Management in Construction, Istanbul, Turkey

Makýš P. (2002) Metodika tvorby časového plánu výstavby pri zohl’adnení vplyvu pracovného prostredia, In Proceedings of $11^{\text {th }}$ section of VII. international scientific conference on $50^{\text {th }}$ anniversary of founding of the Technical University of Košice, Faculty of Civil Engineering TU Košice, Slovakia 